\title{
PREPOSITIONAL ADVERBS
}

\section{Stefka Petrova, stefi38@abv.bg}

\author{
Sofia University "St. Kliment Ohridski", Bulgaria
}

\begin{abstract}
Adverbs are one of the most intriguing categories of language in terms of composition, morphological characteristics, syntactic function, origin, usage and others. When we look at the spelling and meanings closely, number of contradictions are found. The paper examines compound adverbs in Bulgarian grammar which are formed with particularly prepositional prefix such as "HA; OT; $\triangle O$ ". The examination was carried out according to five dictionaries of the Bulgarian language and based on 20 adverbs from the Official Spelling Bulgarian Dictionary (ОПРБЕ) additionally including other adverbs related to the final goal.
\end{abstract}

Keywords: adverbs, composition, compound adverbs, spelling, usage

\section{ПРЕАЛОЖНИ НАРЕЧИЯ}

\section{Стеорка Петрова, stefi38@abv.bg}

Софиийски университет „Св. КАимент Охридски”, България

Резюме: Наречията са еАна от най-интересните категории на езика по състав, морорологична характеристика, синтактична функция, произхол, употреба и Аруги. ПоглеАът Към тях С оглеА на правописа и на значението им показва, че има редица противоречия. В работата се разглежлат сложните спореА българските граматики наречия, образувани с преАлозипреАставки НА, ОТ, АО в пет речника на българския език и се изказват препорьки относно писането им. Изследването е базирано върху 20 наречия, изванени от Офрициалния правописен речник на българския език (ОПРБЕ), АоПъАнени с някои Аруги, свързани с нашата цел..

КАючови Ауми: наречие, сьстав, сложно наречие, правопис, употреба

\section{I. УBOA}

Наречието като част на речта и на изречението се отличава с редица особености, специфиични и интересни от глеАна точка на езиковеда. 
От морфоллогично гледище, т.е. според морфрологичната к^асификация го отнасят кьм неизменяемите думи, макар и $ы$ а не е напьлно неизменяемо - качествените наречия и тези за място напр. могат $\Delta$ а се степенуват. А отАелни наречия имат по Ава-три варианта според начин на образуване, което не се смята, разбира се, за изменение. От синтактична гледна точка го определят като самостойна Аума. Така то стои на границата межАу тези Ава вида класификации, влизайки в еАната група и излизайки от Аругата, което може $А$ с се виАи сполучливо илюстрирано от профр. Пашов (Pashov, 1999: 61), показвайки го и тук. [Фиг. 1]

\begin{tabular}{|c|c|c|}
\hline \multicolumn{3}{|c|}{ 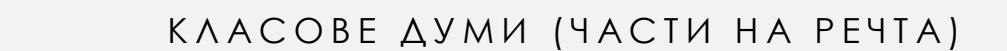 } \\
\hline $\begin{array}{l}\text { Морфоологична } \\
\text { класификация }\end{array}$ & $\begin{array}{l}\text { Семантично-граматична } \\
\text { класиффикация }\end{array}$ & $\begin{array}{l}\text { Синтактична } \\
\text { класификация }\end{array}$ \\
\hline Изменяеми & $\begin{array}{l}\text { 1. Сьществително име } \\
\text { 2. Прилагателно име } \\
\text { 3. Числително име } \\
\text { 4. Местоимение } \\
\text { 5. Глаго^ }\end{array}$ & Самостойни \\
\hline \multirow[t]{3}{*}{ Неизменяеми } & 6. Наречие & \\
\hline & $\begin{array}{l}\text { 7. Предлог } \\
\text { 8. Съюз } \\
\text { 9. Частица }\end{array}$ & Несамостойни \\
\hline & 10. Межлуметие & Странични Ауми \\
\hline
\end{tabular}

Фиг. 1. КАасове Ауми

На второ място, от Семантична ГАеАНа точка то е многопАастово. По характер на признака, който изразяват, наречията се Аелят на шест вила, а по значение - на селем (Kutsarov, 1998: 353). Р. Русинов говори при леление на наречията от семантично-морфологично гледище за пет виАа, включвайки като отАелен виА местоименните наречия (Rusinov, 1983: 389). Спореа мен местоименните наречия и местоименията, както и спореА някои Аруги езиковеАи, би трябвало $а$ व се отАелят в еАна група като Аублиращи Ауми, което е предмет на отлелна публикация (Petrova, 2013: 83-84). Наречието е би^о и тема на Аокторска Аисертация от Ст. Георгиев (Georgiev, 1977), резултатите от която вижАаме отразени в самостоятелния му труА "Морфрология на българския книжовен език”, 
където разглежАа наречията като "пьлнозначни изменяеми Ауми" и ги Аели на обстоятелствени И определителни, както И всички Аруги изследователи. Няма $\Delta$ а се спирам на полробното деление на наречията там, ще цитирам само мнението му за неизменяемостта на наречието, „която може $а$ а се разглежАа като особен рол граматичност. Може $\Delta$ a се предполага, че при такава аморонност на орормата нараства семантичният и категориален дял на мороремните елементи в мотивировката на синтагматичните значения, че семантичните компоненти придобиват особено мордематично обвързване" (Georgiev, 1999: 84), както и да се разбира това. Явно се има предвил освен посочените вече характеристики на наречието и това, че то означава признак на действие, на друг признак или на предмет, както и многобройните начини за образуването му, при което се появяв омонимия с почти всички прилагателни имена в среАен род.

\section{ИЗАОЖЕНИЕ}

Оставям настрана теоретичните вьпроси около наречието и се концентрирам главно върху прелложните местоименни и неместоименни наречия, представляващи трудност или съмнение по отношение на писане - слято или разделно, свързано гАавно със семантичното Аетайлизиране на означавания признак. Ще разглелам наричаните сложни наречия (образувани от преАлог п^юс наречие или име, които спореА мен неправилно се определят като сложни), образувани с пред^озите НА, АО, ОТ, ЗА, ПО. Направих пьАна изваАка на наречията с преАлог НА в Оорициалния правописен речник (ОПРБЕ: 2012) и сверих наличието на определен брой от тях в Аруги речници, без Аа гоня пьлнота. Извадката ми включваше 20 наречия.

Проверих свързаността на всички с означените по-горе преАлози И установих, че преАлозите ПО и ЗА не образуват фронологично еАинство с избраните на случаен признак наречия, с изкючение на един пример при ЗА - заеАно. А преАлогът ПО приема при някои (в нашата изваАка наречията за място) ффункция на частица за степенуване. Ето наречията От ОПРБЕ: [Фиг. 2] 


\begin{tabular}{|c|c|c|c|c|}
\hline HA & $\Delta O$ & OT & ПО & $3 A$ \\
\hline Навътре & - & Отвътре & & - \\
\hline Навън & - & Отвън & - & - \\
\hline Насам & - & Отсам & - & - \\
\hline Натам & Аотам & Oттам & - & - \\
\hline Нашир & - & - & - & - \\
\hline НаА^ъж & - & - & - & - \\
\hline Насън & - & - & - & - \\
\hline Наяве & - & - & - & - \\
\hline Harope & Aorope & Otrope & - & - \\
\hline HaAony & - & ОтАолу & - & - \\
\hline НаАясно & - & ОтАясно & - & - \\
\hline На^яво & - & От^яво & - & - \\
\hline Навеки & Аовеки & - & - & - \\
\hline Накрак & - & - & - & - \\
\hline Наполовина & - & - & - & - \\
\hline Haeanò & - & - & - & Заеано \\
\hline Наново & - & Отново & - & - \\
\hline Наясно & - & - & - & - \\
\hline Haym & - & - & - & - \\
\hline (Тук) & Аотук & Оттук & - & - \\
\hline
\end{tabular}

Фиг. 2. Наречия от ОПРБЕ

Таблицата ми дава право да направя извода, че най-много сложни наречия се образуват с преАлог НА, слеАват образувани с преАлог ОТ и сравнитеАно Малко с преАлог АО. В тази си фрункция преАлозите изпьлняват роля на представки. Заенно не се свързва с посоченото наречие в ОПРБЕ наеАноे, което разглежАам като образувано от числителното еАно + на, но в тази форма - за̀енно - го срещам в Аругите прегледани от мен речници. Аа видим как са представени там същите наречия. [Фиг.3] 


\begin{tabular}{|c|c|c|c|c|}
\hline ОПРБЕ & ПпР 1976 & БТР 1955 & CTP 1995 & ПгР 1975 \\
\hline Навътре & Навьтре & Навьтре & Навьтре & Навьтре \\
\hline Навън & Навьн & Навьн & Навън & Навън \\
\hline Насам & Hacam & Насам & Насам & Насам \\
\hline Натам & Натам & Натам & Натам & Натам \\
\hline Нашир & Нашир & Нашир & Нашир & Нашир \\
\hline Ha $\Delta \wedge$ bж & Ha $\triangle \wedge b ж$ & Ha $\triangle \wedge b ж$ & $\mathrm{Ha} \Delta \wedge \mathrm{b} *$ & Ha $\triangle \wedge$ bж \\
\hline Насьн & $\mathrm{HacbH}$ & - & $\mathrm{HacbH} / \mathrm{e}$ & $\mathrm{HaCbH}$ \\
\hline Наяве & Наяве & Наяве & Наяве & Наяве \\
\hline Нагоре & Harope & Harope & Нarope & Harope \\
\hline $\mathrm{Ha} \Delta \mathrm{O} \wedge \mathrm{y}$ & Ha $\Delta O \wedge y$ & HaAO^y & HaAO^y & HaAO^y \\
\hline $\mathrm{Ha} \triangle 9 \mathrm{CHO}$ & $\mathrm{Ha} \triangle 9 \mathrm{CHO}$ & $\mathrm{Ha} \triangle я \mathrm{CHO}$ & $\mathrm{Ha} \triangle \mathrm{ACHO}$ & $\mathrm{Ha} \triangle \mathrm{gCHO}$ \\
\hline На^яво & На^яво & На^яво & На^яво & На^яво \\
\hline Навеки & Навеки & Навеки & Навеки & Навеки \\
\hline Накрак & - & Накрак & - & - \\
\hline Наполовина & Наполовина & Наполовина & Наполовина & Наполовина \\
\hline HaeAHò & Hae $\Delta \mathrm{HO}$ & Hae $\Delta \mathrm{HO}$ & Hae $\Delta \mathrm{HO}$ & Hae $\Delta \mathrm{HO}$ \\
\hline Наново & Наново & Наново & Наново & Наново \\
\hline $\mathrm{HaяCHO}$ & - & - & Наясно & $\mathrm{HaяCHO}$ \\
\hline Haym & - & Наум & Наум & Hayм \\
\hline (Тук) & - & - & - & - \\
\hline
\end{tabular}

Фиг. 3. Наречията в разглежАаните речници

От така показаното сравнение межлу няколко речника може $А а$ се направи заключение, че свьрзването с преллог НА заема стабилно място в българския език при образуването на наречия. Като незатвьрдено и сравнително ново може да определим тук само наречието накрак. Аипсата на насън в БТР може $а$ а се обясни с фокта, че там е посочено наречиено насьне, както и в СБР, но там имаме и Авете наречия. Явно насъне е по-старата орорма на наречието.

Остава Аа вилим разликата межлу основните и предложните наречия, защото няма сьмнение, че в езика се употребяват и Авата вида. Ще си послужа с конструирани примери. 
1. Вън и навън. Основното, мотивиращото наречие вън спореа мен означава място, има пространствено значение, а производното навън - значение за Авижение. „Ще изляза вън Аа видя какво става”. „Вън е страшно студено". И: „Ще изляза навън Аа видя какво става”. „Навьн е страшно студено". Разликата е малка, но е налична и се Аолавя от носителите на българския език, макар че сьществува Ао голяма степен синонимия. При „Вьн е страшно студено" и „Навьн е страшно стулено” синонимията е пьлна, може $а$ се търси разлика само в стилистичен смисьА.

2. Горе и нагоре. Горе изразява пространствено значение, а нагоре - посока. „Горе има гора”. „Върви нагоре и ще стигнеш Ао гората". Разликата тук е по-ясна, значението на Авете наречия е поотчетливо. „Нагоре има гора" има смисьА, но „Вьрви горе и ще стигнеш Ао гората" е алогично изречение, превьрнато в такова от глагола стигна.

3. ^яво и наляво. Тук може и трябва да прибавим още елно наречие - в^яво. Аяво, както и Аясно, не фуункционират като наречия. Отношението е прилагателно име и наречие. Ще съпоставям наречията вляво и наляво. ВАяво означава повече място, наляво - повече посока. Но синонимията тук е в много по-висока степен. "Трьгни вАяво” и „Трьгни на^яво". „Музеят е в^яво от п^ощаАа" и „Музеят е на^яво от п^ощаАа". Изборьт сякаш зависи от контекста, от сьсеАните Ауми. ПоАобни наречия са нальлго, нашироко, нависоко, накьсо и лруги.

4. Сьн и насьн. Пак имаме не две наречия, а сьществително и наречие. Такива случаи от нашия корпус са крак и накрак, шир и нашир, ум и наум, верев и наверев и др. Употребата тук е без проблеми:

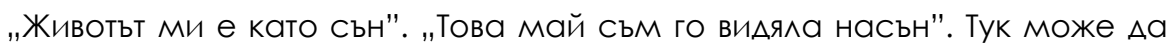
намерим основанието защо не се сочи насьн като наречие в БТР. Там е посочено наречието насьне, което се явява като вариант на насьн в СТР и в ПГР. Аруги такива преА^ожни наречия, образувани с преА^ог п^юс съществително име, всъщност обратно, от съществително име плюс преАлог, са безброй, накуп, накрьст, напук, налице и лруги.

5. *А^ьж и нал^ьж. Мотивираща дума без преллог-представка не съществува. В моя корпус, а и реално в езика, такива наречия са малко: наяве и на+*яве, навеки и на+ *веки, насита, напреки, наизуст и Аруги. 
Оставям извьн наблюдение наречията, образувани от Ава пре $\wedge$ ога - назал, напреА, Аокъм, накъм и Аруги, както и налве, начаса и някои Аруги, тъй като не разглежАам произхола на наречията. Винаги поинтересни за научно изследване обаче са Аумите, които се отклоняват от правилото. В граматиките се сочат като изключения, архаизми, неологизми и Аруги. Напр. има наречие наум, а няма *наглас, сочи се наречието нависоко, а не се употребява и не се сочи *наниско, има наречие накрак (само ОПРБЕ), а няма *нарька, *на машина, има Аовчера, няма ${ }^{*}$ Аоутре и $А$ Анес и прочие. Не са образували сложно наречие редица предложни изрази, като на тъмно, на светло, на живот, Ао живот, на смърт, на светлина, на тъмнина, на музика, на тишина, на ралио, по къра, по мрак, по вечеря, по обел, $о$ обел, на плалне, п^алне, за сега и много Аруги, които изпьлняват в изречението служба на обстоятелствено пояснение.

\section{ЗАКАЮЧЕНИЕ}

Като изключим местоименните наречия, кьлето предлозитепредставки са се слели с мотивиращото безпредложно наречие отлавна, разумно е за правописа да се приеме слелното правило: ако има реално съществуваща Аума в езика - наречие, съществително, прилагателно и числително име - като втора съставна част, $а$ а се пише разделно, преАлог плюс сьответната Аума: на обеА, на пьт, по пьт, $А$ о утре, за винаги, Ао към, от зал, на кръст, без брой, на високо и т.н.

Различният правопис винаги създава затруднение. Започвам Аа пиша изречение, чието начало е наскоро/на скоро. Извеннъж ме обхваща съмнение как се пише - слято или разделно. Отварям речника, вижАам и продьлжавам мисьлта си. Но нали не винаги речникът ни е поА ръка (а тук как е - слято или разделно, пак правя справка) и така губя много време. Ще ми възразите, че ако няма на близо (отново имам нужАа от справка) правописен речник, може Аа се погледне в интернет. Но и това не става бързо и ако се налага често $а$ а се прехвърляме ту тук, ту там, пак става въпрос за губене на време. Затова препорьчвам $\Delta а$ се пишат обстоятелствените пояснения, изразени с наречие или име п^юс предлог, винаги разделно, а при местоименните наречия $\Delta а$ се Аопуска 
Авояко писане, което всъщност и сега е така: Минете оттук, моля! и Минете от тук, моля! Но и за там е валидна тази препорька.

Съществуването на Авойни прави^а не полпомага нито правописа, нито езика и неговото съществуване. Евентуално очертава посоката, в която трьгва развитието на езика, но няма гаранция за това. Трябва $\Delta а$ се прецени какво се печели и какво се губи с далено ново положение и тогава да се приеме или препорьча. Какво печели българският език с това, че трябва $\Delta а$ се пише нависоко, но на ниско, наум, но наглас и прочие. Нищо, само се появяват условия за сьмнение и колебание. СпореА мен се съзАават и излишни трудности, необхолимо е $\Delta$ a се запомнят ненужни правила.

\section{РазглеАани речници:}

БТР 1955: Бъмгарски тълковен речник. Автори: ^. АнАрейчин и Аруги. С., „Наука и изкуство”, 1955.

ОПРБЕ 2012: Одрициален правописен речник на българския език. Авт. Колектив пол ръков. На профр. Афрн Вл. МурАаров. С., Просвета, 2012. ПгР 1975: Пашов, П. и Хр. Първев, Правоговорен речник на българския език. С., „Наука и изкуство”, 1975.

ПпР 1976: Правописен речник на българския книжовен език. 8-мо стер. иза. Състав: Анрлейчин, А., В^. Георгиев, Ив. Аеков, Ст. Стойков. С., „Наука и иАкуство", 1976.

СТР 1995: Съвременен тълковен речник на българския език с и^юстрации и при^ожения. 2-ро прер. и Аоп. изАание. Автори: Ст. Буров, В. Бонджолова, М. Илиева, П. Пехливанова. Отг. рел. Ст. Буров. В. Търново, „ЕАПИС”, 1995. 


\section{LITERATURE (ヘИTEPATYPA)}

Georgiev, St. (1977) System of the dialect in the modern Bulgarian literary language. Abstract of a dissertation for obtaining the scientific degree "Doctor of Philology". Sofia; 1977. [(Георгиев 1977) Георгиев, Ст. Система на наречието в съвременния български книжовен език. Авторедрерат на Аисертация за получаване на научната степен „Аоктор на орилологическите науки”. С., 1977 г.].

Georgiev, St. (1999) Morphology of the Bulgarian literary language. 4th edition. $V$. Tarnovo; 1999. [(Георгиев 1999) Георгиев, Ст. Мрофрология на българския книжовен език. 4-то издание. В. Търново, изА. „Абагар”, 1999].

Kutsarov, Iv. (1998) Boyadzhiev, T., Iv. Kutsarov, J. Penchev, Contemporary Modern Bulgarian Language. Phonetics, lexicology, word formation, morphology, syntax. Ed. of Corresponding Member Prof. Dr. Todor Boyadzhiev. Sofia; 1998. [(Куцаров 1998) ^. Боялжиев, Т., Ив. Куцаров, Й. Пенчев, Съвременен български език. Фонетика, ^ексикология, словообразуване, морфология, синтаксис. Пол реА. на ч^.-кор. Профр. А-р Толор Боялжиев. С., изА. къща „Петър Берон", 1998]

Pashov, P. (1999) Bulgarian Grammar. Plovdiv. [Пашов 1999. ([Пашов 1999) Пашов, П. Българска граматика. ПА, изА. къща „Хермес”, 1999].

Petrova, St. (2013), Morphological structure of words, Nouns. Sofia, 2013. [(Петрова 2013) Петрова, Ст Морорологични ситнежи. Имена. С., АСПА, 2013].

Rusinov, R. (1983) Grammar of the modern Bulgarian language, Sofia; 1983. [(Русинов 1983) Русинов, Р. Граматика на съвременния български език. Т. 2, морфология. Авт. Колектив. С., БАН, 1983]. 

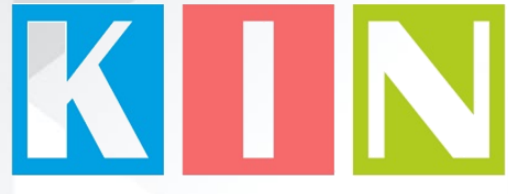

\section{ISSN: 2367-8038}

\section{Съставители \\ Петко Ст. Петков \\ Галина БогАанова}

Материалите в сборника са обект на авторско право. Разрешава се безвъзмезАното ползване на техни електронни/ хартиени копия само за мична употреба или обучение, при пьлно цитиране на текущата страница и слеА писмена Аек^арация от цитиращия за ^ипса на търговски намерения.

Научната поредица е регистрирана в НАЦИА С № 1209

() Авторски колектив, 2021

Техническо реАактори: Калина Сотирова-Вълкова Николай Ноев Паска^ Пиперков

\section{Editors}

Petko St. Petkov

Galina Bogdanova

This work is subject to copyright.

Open and free of charge use of digital/hard copies of publications is granted only for personal or educational use, with full citation of the current page, and after written declaration of the quoting side for notcommercial Intention.

Science series has been registered in NACID with No. 1209

() Authors` Group, 2021

Technical editors:

Kalina Sotirova-Valkova

Nikolay Noev

Paskal Piperkov

\section{ISSN: 2367-8038}

том 7, брой $1(10) / 2021$

vol. 7 , issue $1(10) / 2021$ 